\title{
Changing assessment practice in engineering: how can understanding lecturer perspectives help?
}

\author{
LIZ MCDOWELL ${ }^{\dagger} *$ SU WHITE* ${ }^{*}$ and HUGH C. DAVIS*
}

\begin{abstract}
Assessment in engineering disciplines is typically oriented to demonstrating competence in specific tasks. Even where assessments are intended to have a formative component, little priority may be given to feedback. Engineering departments are often criticized, by their students and by external quality reviewers, for paying insufficient attention to formative assessment. The $\mathrm{e}^{3}$ an project set out to build a question bank of peer-reviewed questions for use within electrical and electronic engineering. As a part of this process, a number of engineers from disparate institutions were required to work together in teams, designing a range of assessments for their subject specialisms. The project team observed that lecturers were especially keen to develop formative assessment but that their understanding of what might be required varied considerably. This paper describes the various ways in which the processes of the project have engaged lecturers in actively identifying and developing their conceptions of teaching, learning and assessment in their subject. It reports on an interview study that was conducted with a selection of participants. It is concluded that lecturers' reflections on and understanding of assessment are closely related to the nature of the subject domain and that it is essential when attempting to improve assessment practice to start from the perspective of lecturers in the discipline.
\end{abstract}

\section{Introduction}

The $\mathrm{e}^{3}$ an project (http://www.ecs.soton.ac.uk./e3an) aims to improve student learning 'through the integration of effective assessment practices into the electrical and electronic engineering (EEE) curriculum', with a special focus on the use of automated methods for both formative and summative assessment. It was acknowledged from the outset that attempting to identify and introduce effective processes to achieve change in assessment practices inevitably raises complex issues related to prevailing institutional and teaching cultures and will therefore face some difficulties. Hence, another of the project's aims is to identify and develop successful approaches to change working through a partnership between educational development and engineering academics. This paper reports on the ways in which the project has developed from the current understanding and assessment practices of EEE lecturers in order to enhance assessment practice.

The project is led by the University of Southampton and the core team also includes EEE academics from partner institutions of Bournemouth University, Southampton Institute of Higher Education and the University of Portsmouth. One significant

${ }^{\dagger}$ School of Health, Community and Education Studies, Northumbria University, Coach Lane Campus, Newcastle upon Tyne NE7 7XA, UK.

University of Southampton, UK.

* To whom correspondence should be addressed. e-mail: liz.mcdowell@unn.ac.uk 
component of its approach is the use of computer-assisted assessment methods and the development and dissemination of peer-reviewed question banks for core topics in the EEE curriculum. The project is funded by the Higher Education Funding Council for England (HEFCE) and the Department for Employment and Learning in Northern Ireland under the Fund for the Development of Teaching \& Learning (http://www. ncteam.ac.uk/projects/fdtl/index.htm), and it thus has a remit to engage EEE academics throughout the higher education sector in England and Northern Ireland. The project aims to do this by involving EEE academics outside the initial core team. It is also developing resource materials such as case studies and guidance notes to assist others in improving assessment practice. These are grounded in the experience and context of the EEE discipline and derived from systematically reviewing and changing assessment practice.

\section{Learning, teaching and assessment in engineering}

Although there are some exceptions (e.g. employing a problem-based learning approach to engineering education), the predominant and traditional approaches to learning and teaching in engineering disciplines in the UK would best be described as teacher directed with a small component of self-directed learning (Biggs 1999). Practices most commonly fall into five parts:

(1) lecture courses: these present and explore theoretical origins and principles;

(2) practical laboratory classes and design classes: these enable students to consolidate theoretical understanding and to practice applying these principles in real-world situations;

(3) example classes or supervision: these enable students to practice and apply their knowledge;

(4) project work: these may be individual or group projects and provide a capstone experience consolidating prior skills and knowledge and enabling the development of higher-level skills such as evaluation and synthesis;

(5) private study.

In all of the universities, students study more than one subject at a time. Most degree programmes are delivered in the form of sets of semester-long modules where the learning outcomes are separately assessed by some mixture of formal examinations and coursework. Where programmes are accredited by professional bodies, the curriculum, teaching methods and the approaches to assessment may, to some extent, be constrained by the accreditation requirements and are typically oriented to demonstrating competence in specific tasks.

The use of assessments for feedback purposes is varied in type, including marked example sheets, lab reports and stage tests. In common with assessment practices in other subjects in the UK, objective tests are not used much. Nonetheless, increasing pressures through greater student numbers and consequent additional demands on staff in terms of marking workload have pointed to the use of objective tests in conjunction with a computer-assisted assessment engine as a possible method of increasing formative assessments. This may be particularly appropriate for subjects that include significant components of applied mathematical theory such as engineering. The use of a formative objective test was one of the motivations that lay behind the $\mathrm{e}^{3}$ an project.

Typically, throughout undergraduate engineering studies formal end-of-module examinations play the major part in assessment. In general, although details vary, these 
exams are mainly of the 'closed book' kind, of about 2-3 hours in length, and require students to answer a small number of questions selected from a larger number on the examination paper. Most of the questions require students to solve an analytical problem using a mathematically-based approach, although questions might also address issues of application, evaluation and synthesis building on the initial problem.

In addition, students may undertake summative courseworks such as compiling laboratory or practical reports, undertaking programming tasks (in computing subjects) and other assignment tasks undertaken individually or in groups culminating in written and/or oral presentations. In the later stages of degree study there is more emphasis on assessment tasks involving 'real' engineering problems and group work, although exams still feature strongly.

In relation to purely formative assessment, it is usual, especially in the first and second years of degree study, for students to be given frequent, often weekly, 'problem sheets' to enable them to practice the analytical methods they need to learn. The problems are similar to or build up towards those that will be found in exams. In some cases problem classes are held so that advice is on hand for students experiencing difficulty with any of the set problems; practice in terms of marking problem sheets and giving feedback is variable.

One area of concern expressed by the academics who were involved in the $\mathrm{e}^{3}$ an project is caused by low levels of attendance or participation at example classes and supervisions. There was a feeling that the heavy emphasis on formal examinations might be resulting in students taking a strategic approach to their learning and predominantly studying just in time for examinations.

\section{3. $\mathbf{e}^{3}$ an Project-process}

From the outset, the project, led by an educational developer, engaged a core group of EEE academics from the partner institutions in discussion of the educational principles underlying the project objectives and involved them in the strategic planning relating to the project focus development and direction.

It was agreed that a large percentage of the questions should be designed to be suitable for direct use in computer-assisted assessments. Others were to be of a more traditional structure such as short answer and example exam questions. It was believed that the questions might then be used in a variety of contexts and either paper or electronic format, for example providing:

- ready-made content in automated tests;

- sample questions to modify;

- a student revision aid;

- content for generating tutorial or example class sheets;

- questions for self-test and diagnostic testing;

- a tutor resource demonstrating types of assessment.

In the first phase of question development, members of the core academic team and academic colleagues from their institutions participated in the authoring and peer review of test questions from four specific topics within the EEE curriculum (analogue electronics, digital electronics and micro-processors, circuit theory and signal processing). There were two stages of preparation for the question authoring. The core team worked through a range of issues associated with the planning, development and authoring of the question banks in a series of monthly meetings. Having agreed themes 
of the four initial banks, syllabus details and past examination papers were used as sources from which to identify key sub-topics within each of the four themes.

The team then identified the key points which arose from this pre-planning process and incorporated them into a half-day 'consultant briefing', which was attended by all potential question authors. The presentations and discussions in the briefings addressed:

- A review of the range of assessment methods which could potentially be used in the EEE curriculum, their advantages and disadvantages and consideration of alternative methods that could be used within the team members' own courses.

- The impacts of assessment on learning.

- The role of formative assessment and feedback in learning.

- Matching test questions to levels of learning (with reference to Bloom's taxonomy).

- Methods of designing objective questions and the types of questions available, e.g. multiple-choice, true-false, matching.

- The most useful way of describing the questions to enable reuse, i.e. specifying the metadata fields in the database.

- The relationship between quality processes and the work of an academic delivering a course.

Question authors worked in theme teams which identified, discussed and agreed the sub-themes within their topic. It had been decided to include questions at introductory, intermediate and advanced level within any given sub-topic. Questions were then to be further differentiated as being appropriate for completion by either a threshold, good or excellent student. These later classifications were taken directly from the Engineering Subject Benchmark Statements (http://www.qaa.ac.uk/crntwork/ benchmark/engineering.pdf). Typically, authors would write one or two trial questions, review them within the group, and then having received feedback on the process and their output, go on to generate a set of approximately 50 questions each, with a target of 300 questions per theme team. These initial questions were used to form the foundation of a question bank for subsequent trialling and use. The processes were also further refined for question development in the subsequent round.

It was observed that by participating in the process of question identification and development, individuals' understanding of student learning and the role of assessment in learning were, to some extent, clarified. However, there were a number of aspects to this observation. Amongst the group of experienced EEE academics there was a wide range of experience and understanding about assessment. When designing the questions, academics frequently focused solely on the subject content to be assessed, being well aware of common difficulties with the subject matter and key content areas that students needed to grasp. They therefore conceived the question design as a means to enhance ways of eliciting student performance and checking that the necessary content had been mastered, but within the confines of their current assessment methods and strategies. Overall approaches to assessment were rarely questioned. The area of assessment where dissatisfaction was expressed was the provision of feedback to students in the course of the academic year. In general, lecturers were satisfied with the summative assessment used, both in-course and end-point exams.

It may well be worth looking more deeply into the particular educational perspective that engineers bring to their activities related to teaching, assessment and the support of learning. Discussion with academics confirmed that their perspective of 
engineering centred on hard-pure knowledge, mastery of physical environment via simulated or real-work contexts with teaching geared towards products and techniques requiring progressive mastery of techniques in linear sequence, and giving importance to factual understanding favouring examinations; multi-choice questions and problemsolving. Their internalized understanding of engineering was wholly consistent with Becher and Trowler's (2001) description of the discipline as a 'hard applied' subject.

In order to explore this aspect of engineering education, data were collected on approaches to teaching using questionnaires (Prosser and Trigwell 1999) for a small number of project participants and engineers who attended dissemination events. The sample was very small and the selection process by no means representative across all engineering lecturers, however the attitudes reported were remarkably consistent and confirmed a largely content-focused view of education with little insight into processes that might underlie student learning.

It might be argued that the particular hands-on approach of learning about educational approaches through an activity such as the design and review of test banks is particularly well suited to the predominant learning and teaching paradigm that exists in engineering. Additionally, the task of formally describing and classifying questions by means of allocating metadata served to make more explicit the assessment functions of a question. It would be interesting to follow through these assertions in further research.

\section{Feedback and formative assessment}

Given the keen interest in the provision of feedback to students amongst the EEE academics, this matter was investigated in more depth through one-to-one interviews with a sample of eight academics from the core team, including individuals from each of the four universities involved. Interviewees had participated in the first stage of the $\mathrm{e}^{3}$ an project by developing objective questions and peer-reviewing the questions as members of small subject-related teams. The interviews told us more about why feedback was considered so important and how it was viewed.

The predominant concern was a dissatisfaction with the feedback that students were given to help in their learning. Providing feedback through tutorials, marking student problem sheets or setting and marking assignments was increasingly difficult to do because courses were becoming larger with more students but no matching increase in the number of staff teaching them. Furthermore, students were more varied in their level of preparation for EEE study at degree level than had been the case in the past. Limited feedback was seen not only as a direct disadvantage to students, but also something which caused teaching difficulties. Lecturers often found it difficult to know how students were coping with particular course elements and were therefore unable to adjust their teaching accordingly. They also had difficulties in monitoring individual students, something which would have alerted them to students who were failing to engage with the course or falling behind.

Lecturers believed that EEE students needed feedback that was frequent and timely and provided a rapid response to the work that they had done and that such feedback would help the students to improve their understanding and performance. Appropriate feedback is often considered to be a useful part of any learning but it was particularly stressed here because of the nature of the students and their engagement with the course. Lecturers were concerned about some students failing to keep up, 
perhaps through not taking the course seriously or not applying themselves consistently. They thought that appropriate, regular assessment and feedback would motivate students, especially as they judged from their experience that students generally were keen to know how they were doing. A number of interviewees reported that few students worked through the regular problem sheets in a thorough way and thought that associated tests might encourage students to take the problem sheets more seriously. They expected such tests to serve a formative purpose but speculated that they might also have to 'count' as summative tests in order to persuade students to do them.

Lecturers did not make very clear distinctions between formative and summative assessment when they talked about practices they would like to adopt and often the two were conflated. They saw frequent testing as a way of serving both summative and formative purposes. Interviewees believed that students would make better progress and achieve better grades if they were tested on small 'chunks' of the course rather than having a high proportion of their grades allocated on the basis of exams at the end of the year or semester. It was felt that this would increase students' confidence in their ability to progress in the course. Some interviewees advocated the adoption of what might be called a 'mastery' approach as ideal in the first year of EEE degrees where students needed to acquire a standard level of fluency in the principles and analytical approaches of the discipline. This type of method would mean students proceeding step-by-step and mastering the required learning in each chunk before moving on. This would necessitate frequent testing and, to some degree, individually-paced study.

Interviewees viewed objective testing, whether conventionally or computer-delivered (CAA), as a solution to the problem of providing more feedback to students. CAA in particular was seen as a way to provide rapid or indeed instant feedback to students without the need to spend staff time on correcting and marking answers. However, in their work on question development for $\mathrm{e}^{3}$ an, more effort had gone into producing questions and answers than to providing feedback. It seemed that lecturers were sometimes prepared to settle for feedback that was little more than a score. Although they saw this as less than ideal, they remained reasonably confident that feedback, even if minimal, would be useful to students.

A number of concerns were expressed about the ways in which objective tests should be incorporated into the courses and whether they should serve summative or formative purposes or both. A major concern was establishing appropriate test conditions, especially for computer-delivered tests, in order to avoid student cheating and collusion. Although these issues are more relevant to summative assessment, similar concerns were raised even in relation to formative assessment. Some lecturers advocated regular testing with marks allocated to keep students working and ensure that they undertook tests and benefited from the feedback obtained. Others were more in favour of formative testing at the outset. They felt that more benefit to learning would be gained by offering students a self-testing resource allowing them to check their own knowledge and take responsibility to do further work and retake tests where needed. However, in many cases they were concerned about whether students would actually take 'optional' tests and so came round to the idea of making tests count by allocating a small proportion of final marks to them just to make sure students did them. From differing initial positions, lecturers came to the view that tests should be both summative and formative, although in each case tests were not thought likely to contribute significantly to final grades or replace normal end-point examinations. 


\section{Discussion}

The experience of the $\mathrm{e}^{3}$ an project shows that lecturers are aware of a number of dilemmas when they consider how best to proceed, but are not fully aware of many of the complexities of the concepts and practice of formative assessment. This is by no means unique to this group of lecturers. The comprehensive review of formative assessment undertaken by Black and Wiliam (1998) shows the difficulties and lack of understanding of some of the complexities demonstrated by many, perhaps even the majority, of teachers and lecturers.

We have found that EEE lecturers have a strong belief in the value of feedback and a concern that students do not receive enough feedback because of current time and resource pressures in universities. However, there are also indications that lecturers may see a very straightforward relationship between the provision of feedback and student behaviour. For many, feedback shows students that they have got the wrong answer, enabling the students to correct their approach or understanding. Given the often discrete and precise nature of information and therefore the related understanding in engineering, it may be that this is a type of 'systems view' of feedback which may derive from ways of thinking in the EEE discipline. If feedback is to be placed within a more developed view of formative assessment, lecturers need to consider the nature of feedback and students' responses to it in more detail. Put simply, being told that you are wrong can lead to a range of less desirable responses such as: ignoring or refusing to believe the information; giving up on learning because you are clearly doomed to fail; or trying to find ways to buck the system and get a better mark next time without putting in any work to improve your knowledge. Key findings in the Black and Wiliam review suggest that qualitative feedback that is focused on the learning tasks and on the performance and progress of the individual learner is more likely to increase motivation for further learning than feedback that is provided in the form of grades or compares the learner's achievement with that of his/her peers.

A related issue is lecturers' concern to use testing and feedback as a means of motivating or forcing students to engage consistently with the demands of their course throughout the academic year. This emerges as particularly important in EEE because of implicit fundamental beliefs about the nature of knowledge in the subject, that it is to a large extent fixed and must be acquired in a cumulative, step-by-step way. Students' application to learning must therefore be sustained otherwise gaps will be left which leave the whole edifice of students' understanding and competence liable to collapse. Similar concerns emerge in other engineering fields, but it is not self-evident that more assessment, even with feedback, will increase students' motivation and application. Baillie and Fitzgerald (2000) noted that the problem of having too many course demands was a de-motivating factor for some engineering students and Case and Gunstone (2001) showed how coping with workload and pressures of time was a severe problem for many engineering students, particularly those who achieved lower grades. Some students may experience the assessment and feedback offered to them as simply more work which makes them less rather than more able to cope with their course.

Many teachers adapt summative assessment approaches when they try to include formative assessment in their courses (Black and Wiliam 1998: 18). The formative assessment may be regular tests of the same type used for summative purposes. There is still debate as to whether it is possible to combine the two purposes in this way and there are claims that where the two are combined, summative purposes always dominate teacher and learner thinking and behaviour (Gipps 1994). For a variety of 
reasons, EEE lecturers often wish to combine formative and summative assessment. Sometimes making tests, which are really designed for feedback and formative purposes, count for marks is seen as a way of forcing students to take the tests; otherwise students might miss out on the learning benefits. Another reason for combining formative and summative assessment is to reward students for the level of achievement they have demonstrated and reduce the reliance on end-point exams. However, this can mean that formative assessment becomes more like summative assessment with, for example, tests undertaken under exam conditions and a student focus on 'banking' the marks obtained rather than acting upon feedback provided.

\section{Conclusions}

Understanding the perspectives of EEE academics on the assessment of student learning is vital in any attempt to improve assessment practice. Firstly, it provides a firm starting point within the wide field of improving assessment practice. The areas where academics perceive that they have needs and experience problems can be targeted. Secondly, changing assessment practice does not merely involve the adoption of a set of new techniques leaving all other matters of pedagogy unaffected. Any significant change in assessment practice requires 'seeing things differently' (a conceptual change) alongside 'doing things differently' (a behavioural change) (Biggs 1999). The $\mathrm{e}^{3}$ an project has both engaged lecturers in doing formative assessment and enabled them to see formative assessment in more developed ways by actively engaging them in the processes of developing student feedback as part of developing the question bank.

We feel that the project has had some success in developing lecturers' views of assessment, especially formative assessment, even beyond the core team. One lecturer said that many lecturers in his department did not even know what formative assessment was when the project started but now they are much more aware of what it is and its value. The ways in which some of the lecturers involved are now implementing formative assessment provide further demonstration. For example, one lecturer has recognized the need for a formative assessment approach that promotes mastery of basic knowledge and competencies in first-year students. He allows students to take incourse tests up to four times until they demonstrate that they have reached the threshold mastery level. Each test is constructed from a random sample of appropriate questions from the $\mathrm{e}^{3}$ an database and is therefore different on each presentation. Students are thus encouraged to work on course material throughout the semester and to use feedback to improve their performance, especially as passing the in-course tests enables them to pass the module. There is, however, an end-point exam which enables the grading of students' performance above this bare pass level. Another lecturer has developed a workbook containing questions drawn from the $\mathrm{e}^{3}$ an database. The questions use various objective testing formats with the correct answer provided, but students are also required to document their working. This is used in group tutorial sessions where a lecturer can provide feedback on the approaches students have taken where they have encountered difficulties with the question. This therefore makes good use of in-built and personal feedback. Furthermore, the lecturer now feels relaxed about students working collaboratively with each other, or seeking assistance to complete the tutorial workbooks since this can be an effective way of learning and the main purpose is formative.

Active participation by lecturers in the $\mathrm{e}^{3}$ an project has enabled them to identify and make changes which they judged to be potentially most effective and which they 
can now directly communicate to their colleagues. The working of an educational developer within the team of academics enabled continued discussion and communication about the objectives of the project from both perspectives. Lecturers' first-hand experience in the project planning and the direct relationship between innovations in assessment and their disciplinary approaches appears to be more effective in changing their understanding than what might have been achieved by more conventional methods such as reading a paper or case study, or attending an academic staff development workshop. The process of $\mathrm{e}^{3}$ an therefore provides a model which others might develop and it has also contributed to understanding perspectives on assessment within engineering disciplines which others can build upon further in other contexts.

\section{References}

BAillie, C. and FitzGERALD, G., 2000, Motivation and attrition in engineering students. European Journal of Engineering Education, 25, 145-155.

Becher, T. and Trowler, P., 2001, Academic Tribes and Territories: Intellectual Enquiry and the Cultures of Disciplines, 2nd edn (Buckingham: SRHE \& Open University Press).

BIGGS, J., 1999, Teaching for Quality Learning at University (Buckingham: SRHE \& Open University Press).

Black, P. and Wiliam, D., 1998, Assessment and classroom learning. Assessment in Education, 5(1), 7-74.

CAse, J. and Gunstone, R., 2001, No time to think-interactions between students' perceptions of time and approaches to learning. Higher Education Close-up 2, Lancaster University, 16-18 July.

GIPPS, C. V., 1994, Beyond Testing: Towards a Theory of Educational Assessment (London: Falmer Press).

Prosser, M. and Trigwell, K., 1999, Understanding Learning and Teaching: The Experience in Higher Education (Buckingham: Society for Research into Higher Education \& Open University Press).

\section{About the authors}

Liz McDowell is a principal lecturer in education at Northumbria University. She works with lecturers, academic managers and on policy and strategy to improve learning, teaching and assessment. She has directed and supported a number of educational research and development projects and was educational advisor to the e3an project. Liz's research interests are in the student experience of assessment and the impacts of assessment on learning.

$\mathrm{Su}$ White is Learning and Teaching Co-ordinator for the Faculty of Engineering and Applied Science at the University of Southampton and a member of the Intelligence Agents and Multimedia (IAM) research group in Electronics and Computer Science. She is project coordinator for the UK Electrical and Electronic Engineering Assessment Network (e3an). Su has been an external advisor to a wide range of high profile learning technology projects and is a member of the steering group for LTSN-ICS, the UK Learning \& Teaching Support Centre for Information and Computer Science.

Hugh Davis is a senior lecturer in the Department of Electronics and Computer Science at the University of Southampton, where he leads the Learning Technologies Research Group (LTG). $\mathrm{He}$ is a founder member of the Intelligence Agents and Multimedia research group. Following a period of ten years or so working at the leading edge of hypertext research, he has returned to his first research area of learning technology with specific interests in the ways in which technology can improve the learning experience, particularly in a research-led learning and teaching environment. 